\title{
Prevalnace of Noise Induced Hearing Loss among Traffic Police Personnel of Kathmandu Metropolitan City
}

\author{
Shrestha I, Shrestha BL, Pokharel M, Amatya RCM, Karki DR
}

Department of ENT HNS

Kathmandu University School of Medical Sciences

Dhulikhel Hospital - Kathmandu University Hospital

Dhulikhel Hospital, Kavre, Nepal

\section{Corresponding Author}

Inku Shrestha

Department of ENT HNS

Kathmandu University School of Medical Sciences

Dhulikhel Hospital- Kathmandu University Hospital

Dhulikhel, Kavre, Nepal

Email: shresthainku@gmail.com

\section{Citation}

Shrestha I, Shrestha BL, Pokharel M, Amatya RCM, Karki DR. Prevalnace of Noise Induced Hearing Loss among Traffic Police Personnel of Kathmandu Metropolitan City. Kathmandu Univ Med J 2011;36(4):274-8

\author{
ABSTRACT \\ Background \\ Noise induced hearing loss ( $\mathrm{NIHL}$ ) is a major preventable occupational health \\ hazard.

\section{Objective} \\ To measure permanent threshold shift in traffic police personnel due to noise \\ exposure and to examine whether it was associated with duration of noise \\ exposure, years of work and risk factors.
}

\section{Methods}

Cross sectional, descriptive study conducted at Dhulikhel hospital, Kathmandu University Hospital in 110 responding traffic police personnel. Detailed history and clinical examination of ear, impedence audiometry and pure tone audiometry was performed.

\section{Results}

Mean age group was 29.82 years; $82(74.5 \%)$ were males and $28(25.5 \%)$ were females. Mean duration of service is 11.86 years. Twenty six (23.6\%) had tinnitus and $39(35.5 \%)$ had blocked sensation in ear. Sixty five (59.1\%) worked between 1019 years. Alcohol and smoking shows positive impact on $\mathrm{NIHL}(p$ value $=0.00$ ). Odds ratio with 95\% confidence interval were 4.481 (1.925-10.432) and 6.578 (2.306$18.764)$ respectively. Among $73(66.4 \%)$ noise induced hearing loss positive cases, bilateral involvement was seen in 45 (40.9\%) and unilateral in 28(25.4\%) cases. Among unilateral cases most were left sided. Hearing threshold at $4 \mathrm{kHz}$ increased according to age and duration of service.

\section{Conclusion}

Traffic police personnel are in constant risk of noise induced hearing loss. Screening for hearing loss is recommended for people exposed to noise.

\section{KEY WORDS}

noise induced hearing loss, traffic police personnel, occupational hazard

\section{INTRODUCTION}

Noise-induced hearing loss (NIHL) is caused by sustained, repeated exposure to excessive sound levels .It accrues progressively and often remains unnoticed until it has reached a certain degree. Any form of sound exposure can lead to NIHL provided there is sufficient intensity and exposure time..$^{1-4}$ The main site of impairment is the outer hair cells of the cochlea, where the damage is irreversible .Very high levels of noise exposure can lead to acute mechanical damage to inner and outer hair cells, but this form of damage is rare..$^{3-6}$

An average traffic sound in the city is about $60-100 \mathrm{~dB}$ by a close observer. 5 When there is exposure to sound level approximately $85 \mathrm{~dB}$, initially it causes temporary dullness of hearing (temporary threshold shift) which usually recovers within 24 hours of exposure; whereas if there is repeated sustained exposure, the threshold shift becomes permanent (permanent threshold shift) due to nerve fiber degeneration. ${ }^{3,7}$

Occupational Safety and Health Association (OSHA) has set $90 \mathrm{dBA}$ as the time-weighted average (TWA) for an 8-hour work day exposure to noise. ${ }^{8}$ This limit according to National Institute of Occupational Safety and Health (NIOSH) is 85 dBA. $^{9}$ After the import of first vehicle in Kathmandu in BS 1958, there has been a steady rise in the number of vehicles and hence with this modernization came the noise pollution.

Objective of the study is to measure permanent threshold 
shift in traffic personnel and to examine whether it was associated with age, duration of service or any risk factors.

\section{METHODS}

This is a cross sectional, descriptive study conducted at Dhulikhel Hospital, Kathmandu University Hospital in June 2009. The protocol was approved in advance by the Institutional Review Committee for medical research ethics. Written informed consent was acquired before the study was carried out.

Audiometric survey was carried out on 110 Traffic police personnel from Kathmandu Metropolitan city. Prior to audiometric assessment, a detailed medical, personal and occupational history was taken. Questionnaires elicited more detailed information on risk factors like smoking, alcohol consumption, acute noise trauma, ototoxic drugs and prior ear diseases. Hearing was measured in a sound treated room by pure tone audiometry (PTA) (air and bone conduction) in the frequencies $0.25,0.5,1,2,4$ and $6 \mathrm{kHz}$ for both ears using Midimate 602 Clinical Audiometer. Measurements were taken using $5 \mathrm{~dB}$ increments. Middle ear pathology was assessed by otomicroscopy, impedance audiometry and air-bone gap. A threshold of $>25 \mathrm{~dB}$ was considered to be hearing loss in any of the above frequencies.

Audiogram of noise induced hearing loss showed air and bone conduction losses both reduced unilaterally or bilaterally with notch at $4 \mathrm{kHz}$. Air conduction with average hearing loss of $>25 \mathrm{~dB}$ at 1,2,3 $\mathrm{KHz}$. Typical audiogram of $\mathrm{NIHL}$ along with exclusion of all other associated causes of hearing loss confirmed diagnosis of NIHL.

As per World Health Organization (WHO,1986), hearing loss was then assessed: less than $25 \mathrm{~dB}$ (normal), 25-40 $\mathrm{dB}$ (slight), 41-60 dB (moderate), 61-80 dB (severe), and above $80 \mathrm{~dB}$ (extreme). According to American Academy of Otolaryngology-Head and Neck Surgery (AAO-HNS)'s definition in 1997 asymmetric hearing loss is defined as $\mathrm{HTL}$ (hearing threshold level) difference of greater than 15 $\mathrm{dB}$ at $0.5,1$, or $2 \mathrm{kHz}$ or $30 \mathrm{~dB}$ at 3,4 , or $6 \mathrm{kHz}$ between two ears.

The audiometric data was analyzed for their sex, age, duration of exposure in hours each day, years of service, hearing loss, symmetrical or asymmetrical hearing loss, risk factors etc.

All the responding traffic police personnel working in Kathmandu metropolitan city with normal looking tympanic membrane and no diseases of the external ear during the time of examination were included in the study. Patient of hypertension, diabetes, history of meningitis, ear surgery (apart from myringoplasty), hereditary loss, usage of ototoxic drugs, any history of head injury or mechanical hearing loss ( air- bone gap > $10 \mathrm{~dB}$ ) were excluded.

Four subjects were excluded from the study, one for chronic suppurative otitis media, two for retracted tympanic membrane and one for impacted cerumen which when removal caused trauma to external auditory canal. Remaining 110 were included in the study.

The data was calculated in an excel spreadsheet which was then exported SPSS (15.0) for analysis. The statistical significance was set to $p<0.05$. Demographic characteristics and study variables were analyzed using descriptive statistics. Means, standard deviations and ranges were reported for continuous variables. Frequencies and percentages were reported for categorical variables.

\section{RESULTS}

Demographic characteristics of the study participants are summarized in Table 1.

Table 1. Socio- demographic characteristics $(n=110)$.

\begin{tabular}{ll}
\hline Variable & Frequency (\%) \\
\hline Age & \\
\hline $20-29$ & $55(50 \%)$ \\
\hline $30-39$ & $41(46.4 \%)$ \\
\hline $40-49$ & \\
\hline Sex & $82.6 \%)$ \\
\hline Males & $82(74.5 \%)$ \\
\hline Females & $28(25.5 \%)$ \\
\hline Years of service & \\
\hline $0-9$ & $38(34.5 \%)$ \\
\hline $10-19$ & $65(59.1 \%)$ \\
\hline $20-29$ & $7(6.4 \%)$ \\
\hline Duration of work per day & \\
\hline$<8$ hrs & $30(27.3 \%)$ \\
\hline$>8 h r s$ & $80(72.7 \%)$ \\
\hline Symptoms & \\
\hline Fullness in ears / Hearing impairment & $39(35.5 \%)$ \\
\hline Tinnitus & $26(23.6 \%)$ \\
\hline None & $45(40.9 \%)$ \\
\hline
\end{tabular}

Among 110 traffic police personnel, mean age group was 29 years (range 23-41). with standard deviation 4.54. Eighty two $(74.5 \%)$ were males and 28 (25.5\%) were females. Mean duration of service in years is 11.86 years with standard deviation of 4.51. Among 110 subjects, 38(34.5\%) of participants worked for < 9 years, 65 (59.1\%) between $10-19$ years and 7 (6.4\%) for $20-29$ years. Eighty (72.7\%) traffic personnel reported that they worked $>$ eight hours per day; whereas 30(27.2\%) reported to work < 8 hours per day. Forty five $(40.9 \%)$ participants perceived their hearing as good. Among the participants; $26(23.6 \%)$ had tinnitus and $39(35.5 \%)$ say that they feel some blocked sensation in ear and have difficulty hearing in noisy environment.

History of tobacco smoking was present 42(38.2\%) respondents. Positive history of alcohol consumption either as binge drinking, weekly or more often was seen 
Table 2. Effects of risk factors on NIHL.

\begin{tabular}{|c|c|c|c|c|c|}
\hline & \multicolumn{2}{|l|}{ NIHL } & \multirow[t]{2}{*}{ Total } & \multirow[t]{2}{*}{ Pearsons $p$ value } & \multirow{2}{*}{$\begin{array}{l}\text { Odds ratio ( } 95 \% \text { Confidence } \\
\text { Interval) }\end{array}$} \\
\hline & Yes & No & & & \\
\hline \multicolumn{6}{|c|}{ Alcohol } \\
\hline Yes & 55 & 15 & 70 & & $4.481(1.925-10.432)$ \\
\hline No & 18 & 22 & 40 & & \\
\hline \multicolumn{6}{|c|}{ Tobacoo smoking } \\
\hline Yes & 37 & 5 & 42 & 0.000 & $6.578(2.306-18.764)$ \\
\hline No & 36 & 32 & 68 & & \\
\hline \multicolumn{6}{|c|}{ Acute Noise Trauma } \\
\hline Yes & 1 & 1 & 8 & 0.621 & - \\
\hline No & 72 & 36 & 108 & & \\
\hline \multicolumn{6}{|c|}{ Family History } \\
\hline Yes & 29 & 9 & 38 & 0.108 & - \\
\hline No & 44 & 28 & 72 & & \\
\hline \multicolumn{6}{|c|}{ History of ototoxic drugs } \\
\hline Yes & 1 & 0 & 1 & 0.474 & $1.514(1.323-1.732)$ \\
\hline No & 7 & 37 & 109 & & \\
\hline Total & 73 & 37 & 110 & & \\
\hline
\end{tabular}

Significant Pearsons $P$ value $<0.000$

in $70(63.6 \%)$ participants. Thirty eight (34.5\%) participants had at least one parent or grandparent with hearing loss and two $(1.8 \%)$ had history of acute noise trauma (e.g.firearm) and one had history of taking ototoxic drug (ATT for Pulmonary tuberculosis).

Alcohol consumption and tobacco smoking have significant association with NIHL.(Table 2) Among the total cases, no NIHL was seen in 37 cases (33.6\%) whereas 73 (66.4\%) had NIHL with a clear dip at $4 \mathrm{kHz}$. Most had mild hearing loss 57(51.8\%), 15 (13.6\%) had moderate whereas only one(0.9\%) had severe hearing loss.(Table 3 )

Table 3. Grades of Hearing loss.

\begin{tabular}{|ll|}
\hline Hearing level & Frequency $(\mathbf{n = 1 1 0})(\%)$ \\
\hline normal $(<25 \mathrm{~dB})$ & $37(33.6 \%)$ \\
\hline Mild hearing loss $(25-40 \mathrm{~dB})$ & $57(51.8 \%)$ \\
\hline Moderate hearing loss ( $41-60 \mathrm{~dB})$ & $15(13.6 \%)$ \\
\hline Severe hearing loss (61- $80 \mathrm{~dB})$ & $1(0.9 \%)$ \\
\hline Total & $110(100 \%)$ \\
\hline
\end{tabular}

Among the ones having hearing loss, 45 (61.6\%) had bilateral loss and 28 (38.4\%) had unilateral loss with 24 on left side $(86 \%)$ when and four $(14 \%)$ on the right side, when it was unilateral loss.

Mean threshold of hearing at four $\mathrm{kHz}$ on right ear is 26.31 with standard deviation 9.42(range 15-70dB). Mean threshold on left ear is 28.95 with SD 10.09 (range 1070dB). (Table 4)

Mean threshold for left ear was more compared to right. This mean threshold increased with increasing age and more duration of service. (Table 4)
Table 4. Hearing threshold at $4 \mathrm{KHz}$ in standard deviation according to age and duration of work.

\begin{tabular}{|lll|}
\hline Age in years & Left $(d B)( \pm S D)$ & Right $(d B)( \pm S D)$ \\
\hline $20-29(n=55)$ & $23.90(7.24)$ & $21.81(6.26)$ \\
\hline $30-39(n=51)$ & $33.33(10.08)$ & $30.68(9.84)$ \\
\hline $40-49(n=4)$ & $42.5(5.00)$ & $32.5(12.58)$ \\
\hline Duration in years & & \\
\hline $0-9$ & $23.81(7.92)$ & $21.97(6.93)$ \\
\hline $10-19$ & $30.76(9.96)$ & $28.00(9.55)$ \\
\hline $10-29$ & $40.0(7.63)$ & $34.2(10.96)$ \\
\hline
\end{tabular}

\section{DISCUSSION}

Noise induced hearing loss ( $\mathrm{NIHL}$ ) is a commonly seen occupational hazard. The sound pressure levels that are required to produce hearing loss are much less compared to what is required to cause discomfort to the exposed individual so the affected person is unaware that his hearing is being damaged. ${ }^{10}$ The development of NIHL is affected by many factors like, individual susceptibility, age, noise level, noise characteristic, duration of exposure, risk factors like smoking associated and use of ear protectors.

We could not find any statistically significant gender difference which was consistent with other studies. ${ }^{11}$ We found prevalence of NIHL in the service group of 10-19 years is comparable to other studies. ${ }^{10,11}$ Age has a cumulative effect on hearing loss. Duration of service gives an additive effect to noise in causing NIHL. So as the age and work duration advances the mean threshold for hearing also increases which is comparable to other studies. ${ }^{12,13}$

In the early stages of NIHL, the speech frequencies are less affected and the patients have a very few symptoms and 
hence they are usually unaware of the deleterious effects of sound. ${ }^{12,13}$ Frequency area $4-6 \mathrm{kHz}$ is usually affected first with maximum at $4 \mathrm{kHz} .{ }^{14}$ Any level of NIHL may muffle high-frequency sounds such as whistles or buzzers and may result in difficulty discriminating speech consonant sounds such as those in the words fish and fist, particularly in noisy environments with background noise, many voices, or room reverberation. ${ }^{13,15}$

Tinnitus was complained by $23.6 \%$ of the subjects. Tinnitus may accompany hearing loss in the patients who have inner ear disorders. ${ }^{5,16}$ In a study among the engineers in American construction industry $\mathrm{O}$ Hong et al found more than $65 \%$ of participants perceived their hearing was good, about $38 \%$ indicated they had ringing or buzzing in their ears, and over $60 \%$ reported a problem understanding what people say in noisy environments. ${ }^{13} \mathrm{O}$. Hong et al in another study on fire-fighters in the US reported that $85 \%$ of his participants had good hearing. ${ }^{17}$

Table 5. Comparision between various studies.

\begin{tabular}{|lll|}
\hline Study & Study Population & $\begin{array}{l}\text { NIHL Prevalance } \\
(\%)\end{array}$ \\
\hline Nair et al $^{10}$ & Air personnel & 22.9 \\
\hline Md Yusuf Haider et al $^{12}$ & Textile mill worker & \\
& Generator department & 46.67 \\
\hline Ruiker et al ${ }^{18}$ & Dyeing department & 37.5 \\
\hline Deepak et al ${ }^{19}$ & Textile mill worker & 33.7 \\
\hline Foluwasayo et al $^{20}$ & Traffic personnel & 21.0 \\
\hline & Steel roll mill worker & 28.2 (better ear) \\
\hline Freida et al ${ }^{21}$ & & 56.8 (worse ear) \\
\hline Present study & Dentist (Belgium) & 19.6 \\
\hline
\end{tabular}

World Health Organization estimated that at a global level occupational noise exposure was the cause of the hearing impairment in one-sixth (16\%) of those people with a moderate or greater hearing loss. Internationally, contribution of occupational noise exposure to total deafness rates is approximately seven\% in the most developed nations and $21 \%$ in developing regions. ${ }^{3}$

On the analysis of severity of hearing loss most of the personnel had mild hearing loss $57 \%$, with $15 \%$ having moderate hearing loss and $1 \%$ with severe loss. This is comparable to study on Indian air force personnel where most had mild to moderate loss and only $24 \%$ had severe loss. $^{10}$

Cigarette smoking may affect cochlear blood supply because it causes peripheral vascular changes, such as increased blood viscosity and reduced oxygen availability. Therefore, smoking and noise may act synergistically. ${ }^{22-24}$ We found the prevalence of NIHL among the smokers to be higher 37 out of 42 (88) which is comparable to Gholamreza et al where the percentage of workers with difference between hearing threshold levels at $4000 \mathrm{~Hz}$ and $1000 \mathrm{~Hz}$ of greater than or equal to $30 \mathrm{~dB}$ in both ears was $49.5 \%$ in smokers and $11.2 \%$ in non smokers. ${ }^{22}$

Hearing loss caused by impact noise /acute noise trauma is an important factor which corresponds well with subjective hearing loss and tinnitus. In contrast to hearing loss from occupational noise, it occurs often in only one ear and predominantly at the frequency of $4 \mathrm{KHz}$. Having increased hearing threshold due to acoustic trauma might lead people to be more susceptible to noise. ${ }^{25,26}$ Systemic ototoxic drug, streptomycin was taken by one as a part of anti-tuberculosis treatment. This may act synergistically with noise to worsen hearing loss. ${ }^{27}$

Bilateral hearing loss (40.9\%) was commonly seen in this study. Among some personnel with unilateral hearing loss, left ear (24\%) was involved more than right (4\%). This is comparable to study among operating engineers by Rop et al and Oi Saeng Hong who also show left sided predominance. ${ }^{12,13}$ Nagaris et al also showed approximately half had bilaterally symmetric NIHL as in present study and $34.2 \%$ had left side predominance. ${ }^{28}$ But it is contradictory to the study by Nair et al where right sided hearing loss was predominant. ${ }^{10}$ The left sided asymmetry may be secondary to biological difference of a less active acoustic reflex on the left ear or may be the higher otoacoustic emission amplitude on the right side due to its more intense auditory efferent system. ${ }^{28,29}$

NIHL is permanent and cannot be cured resulting in significant monetary costs and human suffering. ${ }^{13}$ Fortunately, it can be prevented. Replacing and modifying old vehicles and their horns to decrease noise level should be the priority, but it is not always possible. Using HPD (hearing protecting device) as advised by other authors is also not feasible for such a profession. ${ }^{30-33}$ Restricting the duty hours to $<8$ hours / day, decreasing the number of working days a week, avoiding the risk factors like alcohol, smoking, acute noise trauma, ototoxic drugs, taking good ear care and periodically getting hearing evaluated may help in some extent.

The strength of the study is the socio-demographic data collection and the number of personnel having similar job, fact that these traffic personnel where medically and audiologically fit before they joined their duty. However larger study would be desirable for more precise risk estimates.

\section{CONCLUSION}

The study showed that NIHL was common in traffic police personnel due to the nature of their job. Study has proven that increasing age, more duration of service, alcohol intake and tobacco smoking are significant risk factors causing noise induced hearing loss. Without proper knowledge and intervention, we are all at risk of developing NIHL sooner or later. The need of the hour is to create awareness among all the city dwellers regarding the condition and prevent it as best as possible. 


\section{ACKNOWLEDGEMENT}

The authors are grateful to Mr Seshananda Sanjel and Mr Kedar Manandhar from community medicine department for helping in statistical analysis.

\section{REFERENCES}

1. World Health Organization (WHO). Occupational and community noise. Fact sheet No. 258. Geneva: WHO; 2001.

2. WHO. Occupational noise: assessing the burden of disease from work-related hearing impairment at national and local levels. Environmental Burden of Disease Series, No. 9. Geneva: WHO; 2004.

3. Thorne PR, Ameratunga SN, Stewart J, Reid N,Williams W, Purdy SC, Dodd G, Wallaart J. Epidemiology of noise-induced hearing loss in New Zealand. Journal of the New Zealand Medical Association 2008;(121):1280.

4. Nandi SS, Dhatrak SV. Indian journal of occupational and environment medicine Occupational noise-induced hearing loss in India 2008; 12(2):53-56.

5. Scientific Committee on Emerging and Newly Identified Health Risks (SCENIHR). Potential health risks of exposure to noise from personal music players and mobile phones including a music playing function. September 2008.

6. Bamiou D, Lutman ME. Interaction of NIHL and ageing: epidemiological aspects. In: Luxon L,Prasher D (eds). Noise and its effects. Chichester: John Wiley, 2007; 64-84.

7. Dobie RA. Medical-Legal Evaluation of Hearing Loss (2nd ed.). San Diego: Singular / Thompson Learning; 2001.

8. Occupational Safety and Health Administration (OSHA): Final regulatory analysis of the hearing conservation amendment. Report No. 723-860/752 1B3. Washington, DC: Government Printing Office; 1981.

9. NIOSH. A proposed national strategy for the prevention of noiseinduced hearing loss, Chapter 8 in: Proposed National strategies for the Prevention of Leading Work-Related Diseases and Injuries, Part 2. Cincinnati, $\mathrm{OH}$ : National Institute for Occupational Safety and Health; 1988.

10. Nair S, Kashyap RC. Prevalence of Noise Induced Hearing Loss in Indian Air Force Personnel. MJAFI. 2009; 65( 3).

11. Mehrparvar AH, Mirmohammadi SJ, Ghoreyshi A, Mollasadeghi A, Loukzadeh Z. High-frequency audiometry: a means for early diagnosis of noise-induced hearing loss. Noise Health 2011 NovDec;13(55):402-6.

12. 12..Md. Haider $Y$, Ahmmad T, Manjur R, Huq AHMZ, Abdullah M. Noise induced hearing loss among the textile industry workers. Bangladesh J of Otorhinolaryngology 2008; 14(2): 39-45.

13. Rop I, Raber A., Fscher G.H. study of the hearing losses of Industrial workers with occupational noise exposure, using statistical methods for the analysis of qualitative data. Audiology 1979; 18: 181-196.

14. Hong OS. Hearing loss among operating engineers in American construction industry. Int Arch Occup Environ Health 2005;78:565574.

15. Hanssen SQ, Thorud E, Aasand G. Noise induced hearing loss and the comprehension of speech in noise. Acta Otolaryngol(suppl) 1979;360:90-95.

16. Smoorenburg GF .Noise-induced hearing loss. In: McCunney R J, Brandt-Rauf P W (eds). A practical approach to occupational and environmental medicine, 2nd edn. Little, Brown and Company, New York.1992; 230-247.

17. Goplen F K, Aasen T, Grønning M, Molvær OI, Nordah SHG. Hearing loss in divers: a 6-year prospective study. Eur Arch Otorhinolaryngol 2011;268:979-985.
18. Hong OS, Chin DL, Ronis DL.Predictors of Hearing Protection Behavior among Firefighters in the United States Int.J. Behav 2011.Dec 8.

19. Ruiker MM, Motghare DD, Vasudeo ND. Evaluation of Hearing Handicap in textile mill employees with noise induced hearing loss. IJO\&HNS 1997; 49(2).

20. Rajenderkumar D. Assessment of traffic noise and its impact on certain personnel.IJO \& HNS Special Issue 1997; 47-50.

21. Foluwasayo E. Ologe $\mathbb{E}$ Tanimola M. Akande T. G. Olajide. Occupational noise exposure and sensorineural hearing loss among workers of a steel rolling mill. Eur Arch Otorhinolaryngol 2006; 263: 618-21.

22. Gijbels F, Jacobs R, Princen K, Nackaerts O, Debruyne F. Potential occupational health problems for dentists in Flanders, Belgium. Clin. Oral Invest 2006;10:8-16.

23. Pouryaghoub G, Mehrdad R, Mohammadi S. Interaction of smoking and occupational noise exposure on hearing loss: a cross-sectional study. BMC Public Health 2007,7:137.

24. Lowe GD, Drummond MM, Forbes CD, Barbenel JC: The effects of age and cigarette smoking on blood and plasma viscosity in men. Scott Med J 1980;25:13-17.

25. Browning GG, Gatehouse S, Lowe GD: Blood viscosity as a factor in sensorineural hearing impairment. Lancet 1986;1:121-3.

26. Rivière S, Schwoebel V, Lapierre-Duval K, Warret G, Saturnin M, Avan $P$, Job A, Lang T..Hearing status after an industrial explosion: experience of the AZF explosion, 21 September 2001, France. Int Arch Occup Environ Health 2008;81:409-414.

27. Sverre Quist-Hanssen . Induced Hearing Loss amongst engineeroom personnel on board Norwegian merchant ships. Acta oto-laryng Suppl 1964:3-25.

28. Chauhan RS, Saxena RK ,Varshey S. The role of ultrahigh-frequency audiometry in the early detection of systemic drug-induced hearing loss. Ear Nose Throat J 2011 May; 90(5):218-222.

29. Nageris BI, Raveh E, Zilberberg M. Asymmetry in noise-induced hearing loss: relevance of acoustic reflex and left or right handedness. Attias J Otol Neurotol 2007; 28:434-7.

30. 29. Newmark M, Merlob P, Bresloff I, et al. Click evoked otoacoustic emissions: inter-aural and gender differences in newborns. J Basic Clin Physiol Pharmacol 1997;8:133Y9.

31. Heupa $A B$, Gonçalves CG, Coifman H.Effects of impact noise on the hearing of military personnel. Braz J Otorhinolaryngol 2011 Dec;77(6):747-53.

32. Stephenson MR, Berger EH, Hager LD, Johnson DL, Lankford JE, Meinke DK, Nadler NB, Stephenson CM. Preventing noise induced occupational hearing loss. American Academy of Audiology. October 2003.

33. McBride D.I .Noise-induced hearing loss and hearing conservation in mining.Occupational Medicine 2004; 54:290-296.

34. Nandi SS, Dhatrak SV. Occupational noise-induced hearing loss in India. Indian journal of occupational and environment medicine 2008;12(2):53-56. 